\title{
The effect of indigestible particles on digestive transit time and colonic motility in dogs and pigs
}

\author{
By CH. CHERBUT AND Y. RUCKEBUSCH \\ Laboratoire de Physiologie, Ecole Nationale Vétérinaire, \\ 31076 Toulouse Cédex, France
}

(Received 11 June 1984 - Accepted 23 November 1984)

\begin{abstract}
1. The myoelectric activity of the colon was examined in three dogs and three pigs when they were given a basal diet or a basal diet plus indigestible particles (IP), $2 \mathrm{~mm}$ in diameter, at $100 \mathrm{~g} / \mathrm{kg}$ dry matter. The mean retention time was determined using coloured discs as a marker added to the daily meal.

2. Colonic electromyograms of dogs and pigs given IP revealed a $30 \%$ reduction in the number of long spike bursts (LSB) when compared with controls. The other components, propulsive migrating spike bursts (MSB) or non-propulsive short spike bursts (SSB), were unchanged. Mean retention time was decreased from $28.6 \mathrm{~h}$ to $17 \cdot 6 \mathrm{~h}$ in dogs and from $129 \mathrm{~h}$ to $94.2 \mathrm{~h}$ in pigs.

3. These changes developed progressively during 3-4 d in both species, suggesting that the reduction in motor activity was an adaptation to the changes in bulk contents.

4. From the decreased motility of the colon linked to the reduction of LSB and paralleled by an increased transit time, it was concluded that one of the functions of the LSB is to impede the passage of digesta.
\end{abstract}

A classical finding in the study of the relation between motility and digestive transit is an increased motility index when the transit is accelerated. For example, the digestive transit in humans, especially for the large intestine (Kirwan et al. 1974), is increased by increased dietary fibre (Harvey et al. 1973). Fioramonti \& Buéno (1980) found that the addition of bran to a milk diet for piglets is accompanied by an accelerated colonic transit. There is an increased motility index, resulting essentially from changes in only one of the components of the electromyogram, the long spike bursts (LSB).

However, it is well-established that constipating agents increase, while laxatives decrease, colonic motility in man and animals. Following the administration of morphine, colonic motility increases, yet faecal output decreases. This suggests that the other components of the electromyogram, i.e. non-propulsive short spike bursts (SSB; Ruckebusch \& Fioramonti, 1980), may be involved, or that the fusion of the LSB into propagative rhythmic bursts (Sarna et al. 1984) may be altered. Another recent finding confirms the unequivocal relation between motility and transit, since a negative correlation was found between faecal bulk and myoelectric spike activity in the proximal canine colon when $\alpha$-cellulose was used as a source of dietary fibre (Burrows \& Merritt, 1983). These seemingly contradictory results may involve a modification of water absorption, but the precise mechanism has not been defined. In preliminary studies using high-fibre diets in pigs, we observed that motility (mechanical or electrical motility index) dramatically decreased while faecal output increased. Similar events were also observed in dogs and developed progressively within 3-4 d in both species.

The purpose of the present experiments was to: (1) define the adaptation of colonic motor activity following a diet change using inert polyethylene particles, (2) evaluate the influence on transit time of this diet when neither water-holding (Stephen \& Cummings, 1979) nor fermentation (Hellendoorn, 1978; Bardon \& Fioramonti, 1983) could be involved. To assess the possible mechanisms involved in an apparently decreased colonic motility accompanied by an increased propulsion of contents, each of the two components of the colonic electromyogram, i.e. SSB and LSB, was taken into account (Ruckebusch \& Fioramonti, $1980)$ and particular attention was given to their temporal organization and propagation. 


\section{MATERIALS AND METHODS}

\section{Animals and diets}

Nichrome electrodes were surgically implanted on the gut in groups of three, $2 \mathrm{~mm}$ apart, in three mongrel dogs $(12-18 \mathrm{~kg})$ and three Large White pigs $(30 \mathrm{~kg})$ according to a technique previously described (Ruckebusch, 1970). Six groups of electrodes were implanted in each dog, one group on the duodenum to evaluate the postprandial disruption and the others at distances from the ileocolonic junction of 15 and $50 \mathrm{~mm}$ (proximal colon), 100 and $200 \mathrm{~mm}$ (transverse colon) and $300 \mathrm{~mm}$ (distal colon). Five groups of electrodes were similarly implanted in each pig, two groups at 20 and $100 \mathrm{~mm}$ from the ileocolonic junction, one group on the centripetal and another on the centrifugal turn of the ascending colon and one group on the descending colon $250 \mathrm{~mm}$ proximal to the rectum. Free ends of the electrodes were directed subcutaneously along the right flank and exteriorized between the scapulas.

The dogs received, at 09.00 hours, a meal of $400 \mathrm{~g}$ dried food (Royal Canin; Quaker, 13002 Marseille, France; (g/kg) 600 dry matter (DM), 320 protein, 180 fat, 40 fibre, 60 ash), mixed with tap water ( 1.5 litres) and, after 2 weeks, $600 \mathrm{~g}$ canned food (Fido; $(\mathrm{g} / \mathrm{kg})$ $200 \mathrm{DM}, 100$ protein, 60 fat, 25 ash and fibre less than 10) with water ad lib. Indigestible particles (IP) of polyethylene ( $2 \mathrm{~mm}$ in diameter) resembling grains of rice (prepared by BP-Chimie, 13117 Lavera, France) were added to the latter diet at 100 and $450 \mathrm{~g} / \mathrm{kg} \mathrm{DM}$. The pigs, at first, received a commercial standard diet (barley weatings and fishmeal) and after 2 weeks they were given a dried milk-substitute diet (commercial diet prepared for calves, $20 \mathrm{~g} / \mathrm{kg}$ body-weight daily; Rental Languedoc, 31770 Colomiers, France) given as soup in a single meal at 09.00 hours. IP were added to this basal diet at $100 \mathrm{~g} / \mathrm{kg} \mathrm{DM}$. Water was available to both dogs and pigs. No refusal of the food offered was noted.

\section{Experimental procedure}

Myoelectric acitivity was recorded during day time for 8 weeks using an eight-channel 'direct writing' polygraph (Reega VIII; Alvar Electronic, 93107 Montreuil, France) at a low recording speed $(25 \mathrm{~mm} / \mathrm{min})$ and time constant of $0.1 \mathrm{~s}$. Concurrent summation of electrical activity at 20-s intervals from two or three electrode sites was obtained by a linear integrator circuit connected to a potentiometric recorder (Latour, 1973). Integrations were used continuously as a monitoring procedure throughout the experiments. Moreover, the activity from the electrode sites on the proximal and distal colon was recorded on a magnetic tape analog recorder (Analog 7; Philips, Holland) to calculate at 5-min intervals the motility index. For that, a microprocessor calculated the quantity of electricity issued every 5 min and gave hourly values expressed as a percentage of the maximal activity recorded during feeding of a standard meal (Latour \& Ferré, 1985). Each dog and pig received IP added to the basal diet at $100 \mathrm{~g} / \mathrm{kg} \mathrm{DM}$ on three occasions for a period of $7 \mathrm{~d}$. One trial was also performed in each of the dogs with IP added at $450 \mathrm{~g} / \mathrm{kg} \mathrm{DM}$.

\section{Transit time}

The mean retention time (MRT) of food residues in the entire digestive tract (mouth to anus) was evaluated by a marker incorporated in one meal. The marker consisted of thirty small flexible discs of coloured polyethylene, approximately $3 \mathrm{~mm}$ in diameter and $0.3-0.4 \mathrm{~mm}$ thick. Faeces were collected three times daily and weighed, and samples taken for DM determination. The excretion of markers $v$. time was recorded and the MRT was calculated according to Castle \& Castle (1956). 
(a)
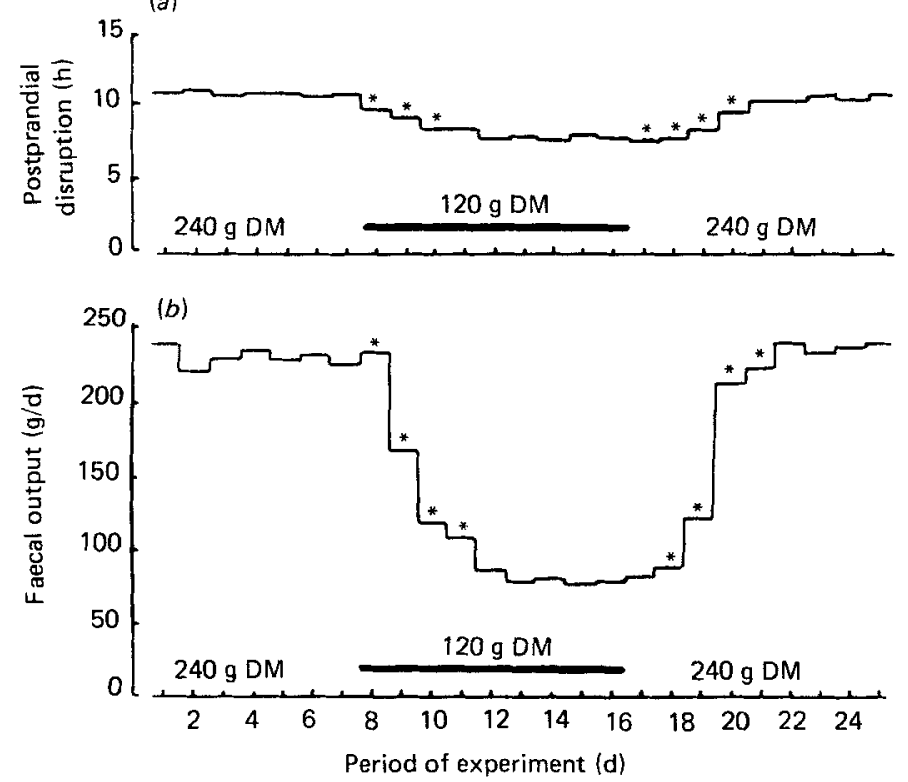

Fig. 1. Adaptive period to a canned diet in the dog receiving dried food. After a change of diet, an adaptation period is required $\left({ }^{*}\right)$. For details of diets, see p. 550. (a) A constant duration of postprandial disruption of the small intestinal myoelectric motility pattern and $(b)$ a regular faecal output were observed after $3-4 \mathrm{~d}$.

\section{Statistical methods}

The statistical significance of the changes in motility index, retention time and faecal measurements, compared with the basal diet, was calculated using Student's paired $t$ test. Results are expressed as mean values with their standard errors.

\section{RESULTS}

\section{Adaptation period for diets}

A period of 2-4 d was required before reproducible effects on intestinal motility and faecal output were obtained. The postprandial disruption of the interdigestive motility pattern represented by a continuous spiking activity on the duodenum (Ruckebusch \& Buéno, 1977) lasted 10-11 h when the dogs received dried food (240 g DM) mixed with water, but only $7-8 \mathrm{~h}$ when they were given canned food $(120 \mathrm{~g} \mathrm{DM})$. The fresh weight of faeces excreted daily following this diet change decreased from 250 (SE 15) g to less than $100 \mathrm{~g}$. Fig. 1 illustrates the time required for stabilization of duodenal motility recordings and faecal output after changing the diet. The return to the previous diet also required $2-3 \mathrm{~d}$ for stabilization. In dogs receiving canned food $(200 \mathrm{~g} / \mathrm{kg} \mathrm{DM})$, the faecal output (including IP) increased progressively from 92 (SE 11) g/d to 137 (SE 22) g/d within $3 \mathrm{~d}$ after addition of IP and output remained constant thereafter. A similar observation was made in pigs when changed from their standard diet to a milk diet and then to a milk diet plus IP. The changes in faecal output were stabilized in 3-4 d.

\section{Transit time and faecal excretion}

The MRT of digesta was determined in dogs and pigs 5 and $6 \mathrm{~d}$ after changing diets. In dogs, the time required for $50 \%$ of the marker to appear in the faeces following ingestion of the canned diet was $28 \mathrm{~h}$ and decreased to $17-20 \mathrm{~h}$, i.e. by approximately $30 \%$, when 
Table 1. Mean retention time (MRT) and faecal excretion in dogs and pigs fed on a basal diet with and without indigestible particles (IP)

(Mean values with their standard errors for three determinations)

\begin{tabular}{|c|c|c|c|c|c|c|}
\hline & \multicolumn{2}{|c|}{ MRT (h) } & \multicolumn{2}{|c|}{$\begin{array}{l}\text { Fresh faeces } \dagger \\
(\mathrm{g} / 24 \mathrm{~h})\end{array}$} & \multicolumn{2}{|c|}{$\begin{array}{c}\text { Dry faeces } \dagger \\
(\mathrm{g} / 24 \mathrm{~h})\end{array}$} \\
\hline & Mean & $\mathbf{S E}$ & Mean & SE & Mean & $\mathbf{S E}$ \\
\hline \multicolumn{7}{|l|}{ Dogs: } \\
\hline Canned diet $\ddagger$ & 28.6 & 0.97 & 92.0 & $11 \cdot 0$ & $59 \cdot 0$ & $9 \cdot 7$ \\
\hline$+100 \mathrm{~g} \mathrm{IP} / \mathrm{kg} \mathrm{DM}$ & $17 \cdot 6^{*}$ & 1.39 & $137 \cdot 0^{*}$ & $22 \cdot 0$ & $75 \cdot 2^{*}$ & $12 \cdot 3$ \\
\hline$+450 \mathrm{~g} \mathrm{IP} / \mathrm{kg} \mathrm{DM}$ & $20 \cdot 36^{*}$ & 0.91 & $170 \cdot 0^{*}$ & $15 \cdot 0$ & $117 \cdot 5^{*}$ & $10 \cdot 6$ \\
\hline \multicolumn{7}{|l|}{ Pigs: } \\
\hline Powdered-milk diet & $129 \cdot 0$ & $6 \cdot 2$ & $85 \cdot 4$ & 9.4 & $52 \cdot 2$ & $7 \cdot 8$ \\
\hline Milk diet $+100 \mathrm{~g} \mathrm{IP} / \mathrm{kg} \mathrm{DM}$ & $94 \cdot 2^{*}$ & 4.9 & $171 \cdot 7^{*}$ & $16 \cdot 5$ & $118 \cdot 0^{*}$ & 12.4 \\
\hline
\end{tabular}

DM, dry matter.

Mean value was significantly different from that for the basal diet: ${ }^{*} P<0 \cdot 05$.

+ Including IP.

$\ddagger$ For details of diets, see p. 550 .

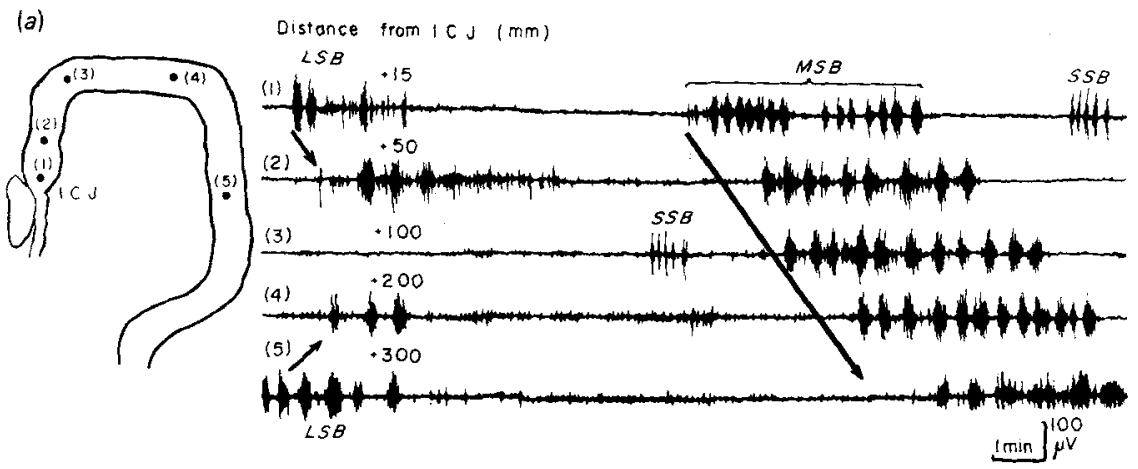

(b)

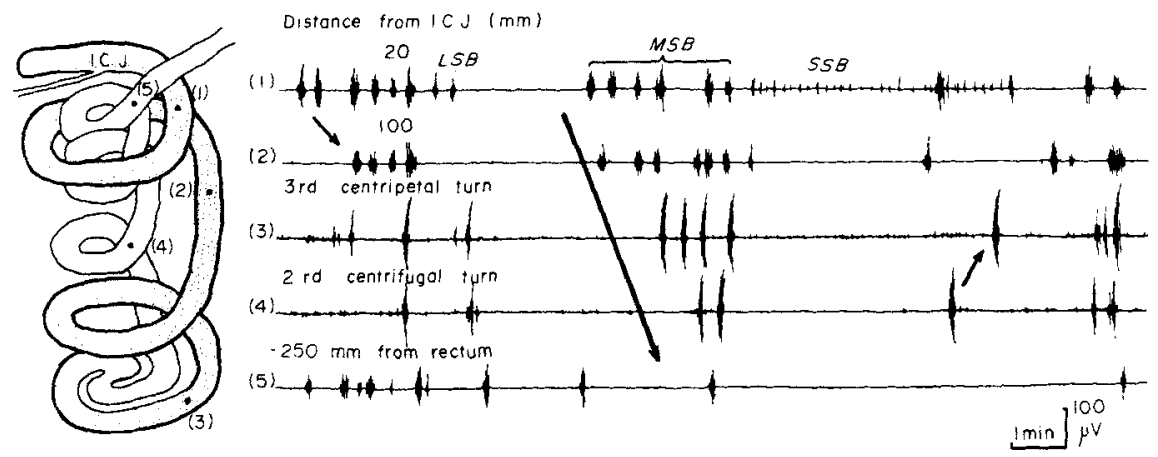

Fig. 2. Characteristics of myoelectric activity (spiking activity) recorded in (a) the dog and (b) the pig from electrode sites on the proximal, transverse and distal colon. Short duration spike bursts (SSB) were localized at one electrode site. Long duration spike bursts (LSB) isolated or in groups of two or three were propagated for short distances in both directions (f). Migrating spike bursts (MSB) occurred as a group of eight to twelve (dog) or three to five (pig) spike bursts similar to the LSB and propagated aborally along the whole colon. ICJ, ileocolonic junction. 
(a)

(b)

Proximal colon ( $+50 \mathrm{~mm}$ from $\mid \mathrm{CJ})$

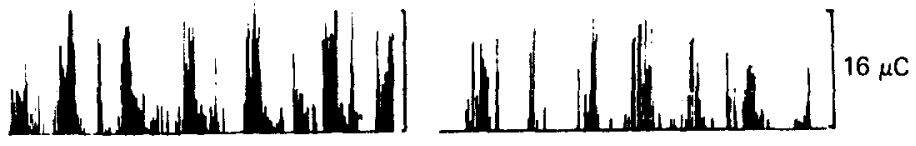

Distal colon ( $-100 \mathrm{~mm}$ from rectum)

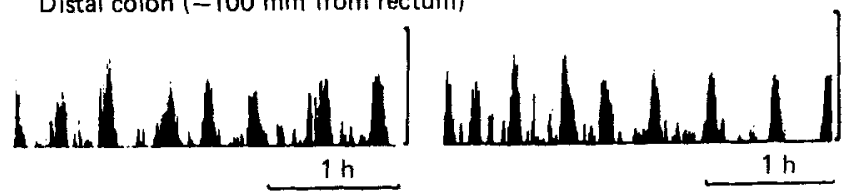

Fig. 3. Motor profile of the colonic myoelectrical activity (integrated record) in the $\operatorname{dog}(a) 5 \mathrm{~h}$ after a meal of canned food and $(b) 5 \mathrm{~h}$ after a meal containing indigestible particles (IP) at $100 \mathrm{~g} / \mathrm{kg}$ dry matter. Note the decreased spiking activity on the proximal colon following the addition of IP to the diet whereas the motor profile on the distal colon remained unchanged. ICJ, ileocolonic junction.

(a)

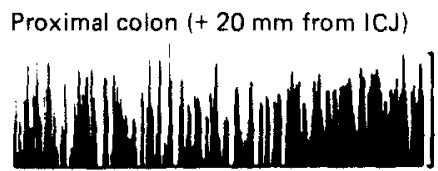

Distal colon $(-250 \mathrm{~mm}$ from rectum)

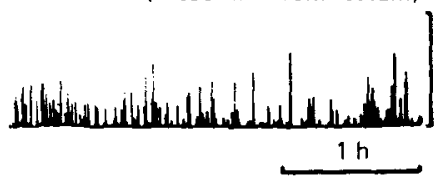

(b)
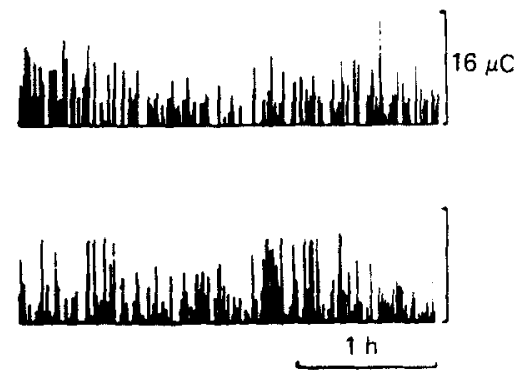

Fig. 4. Motor profile (integrated record) in the pig (a) $5 \mathrm{~h}$ after a powdered milk meal and (b) $5 \mathrm{~h}$ after a powdered milk meal plus indigestible particles. Note the decreased spiking activity on the proximal colon and its slight enhancement on the distal colon. ICJ, ileocolonic junction.

IP were added (100 g/ $\mathrm{kg} \mathrm{DM})$. The MRT of digesta in pigs fed on the powdered milk diet decreased from $129 \mathrm{~h}$ to $94 \mathrm{~h}$, i.e. by $28 \%$ after addition of IP (100 g/ $\mathrm{kg} \mathrm{DM}$ ) (Table 1). Daily faecal excretion increased in dogs from 92 (SE 11) g (canned diet) to 137 (SE 22) $\mathrm{g}$ (canned diet + IP) as well as in pigs from 85 (SE 9) g (powdered milk diet) to 172 (SE 17) $\mathrm{g}$ (powdered milk diet + IP) $(P<0.05)$. In both species, the total faecal excretion of DM increased by much more than the DM added as IP. The faecal output but not the transit time was further increased in dogs when a larger amount of IP $(450 \mathrm{~g} / \mathrm{kg}$ ) was given (see Table 1).

\section{Changes in colonic spike activity}

The colonic myoelectric recordings of both dogs and pigs presented two distinct types of spike burst activity: spike bursts of short duration (SSB) lasting approximately $1 \mathrm{~s}$, and LSB, which lasted 7-14 s (Ruckebusch \& Fioramonti, 1980). While SSB were always localized at one electrode site (Fig. 2), the LSB often occurred as a short sequence (two to four LSB) which was propagated for a short distance in either direction. Sometimes longer sequences of eight to twelve LSB were seen. As such sequences occurred successively on all recording electrodes and at a regular frequency of $3 \cdot 2 / \mathrm{h}$ in dogs on canned diet and $1 \cdot 2 / \mathrm{h}$ in pigs on milk diet, they were termed migrating spike bursts (MSB). In dogs these MSB lasted 5-8 min, giving a clear cyclicity to the integrated spiking record (Fig. 3), and were 
Table 2. Colonic myoelectric activity in dogs fed on a canned diet with and without indigestible particles $(I P) \dagger$

(Mean values with their standard errors for nine determinations, expressed as percentages of the total activity recorded during $8 \mathrm{~h}$ )

\begin{tabular}{|c|c|c|c|c|c|c|}
\hline & \multicolumn{2}{|c|}{ Canned diet } & \multicolumn{2}{|c|}{$\begin{array}{l}\text { Canned diet }+ \\
100 \mathrm{~g} \text { IP/kg DM }\end{array}$} & \multicolumn{2}{|c|}{$\begin{array}{c}\text { Canned diet }+ \\
450 \mathrm{~g} \mathrm{IP} / \mathrm{kg} \mathrm{DM}\end{array}$} \\
\hline & Mean & SE & Mean & $\mathbf{S E}$ & Mean & SE \\
\hline \multicolumn{7}{|l|}{ Total LSB: } \\
\hline Proximal colon & $51 \cdot 40$ & $0 \cdot 27$ & $31 \cdot 18^{*}$ & $0 \cdot 21$ & $31.96^{*}$ & 0.52 \\
\hline Transverse colon & $55 \cdot 57$ & 0.47 & $28 \cdot 78^{*}$ & $0 \cdot 24$ & $26 \cdot 60^{*}$ & 0.37 \\
\hline \multicolumn{7}{|l|}{ LSB (not grouped in MSB): } \\
\hline Proximal colon & $20 \cdot 05$ & $0 \cdot 23$ & $7 \cdot 94^{*}$ & 0.32 & $7 \cdot 56^{*}$ & 0.40 \\
\hline Transverse colon & $21 \cdot 35$ & $0 \cdot 27$ & $6 \cdot 81^{*}$ & 0.32 & $7 \cdot 47^{*}$ & 0.35 \\
\hline \multicolumn{7}{|l|}{ SSB: } \\
\hline Proximal colon & $5 \cdot 72$ & 0.23 & $5 \cdot 94^{\mathrm{NS}}$ & 0.29 & $6.45^{\mathrm{NS}}$ & $0 \cdot 20$ \\
\hline Transverse colon & $11 \cdot 31$ & 0.68 & $10 \cdot 42^{\mathrm{NS}}$ & $0 \cdot 33$ & $9 \cdot 83^{\mathrm{NS}}$ & 0.55 \\
\hline Frequency MSB (sequences/h) & $3 \cdot 2$ & 0.4 & $2.9 \mathrm{Ns}$ & 0.3 & $2 \cdot 7^{\mathrm{NS}}$ & 0.7 \\
\hline
\end{tabular}

LSB, long spike bursts; SSB, short spike bursts; MSB, migrating spike bursts; NS, not significant; DM, dry matter.

Mean value was significantly different from that for the diet without IP: ${ }^{*} P<0.05$.

$\dagger$ For details of diets, see p. 550 .

Table 3. Colonic myoelectric activity in pigs fed on a basal powdered-milk diet with and without indigestible particles (IP)

(Mean values with their standard errors for nine determinations expressed as percentages of the total activity recorded during $8 \mathrm{~h}$ )

\begin{tabular}{|c|c|c|c|c|}
\hline & \multicolumn{2}{|c|}{ Powdered-milk diet $\dagger$} & \multicolumn{2}{|c|}{$\begin{array}{c}\text { Milk-diet }+ \\
100 \mathrm{~g} \mathrm{IP} / \mathrm{kg} \mathrm{DM}\end{array}$} \\
\hline & Mean & SE & Mean & SE \\
\hline \multicolumn{5}{|l|}{ Total LSB: } \\
\hline Proximal colon & $25 \cdot 58$ & $0 \cdot 19$ & $19 \cdot 41 *$ & 0.29 \\
\hline Transverse colon & $22 \cdot 36$ & 0.56 & $17 \cdot 63^{*}$ & 0.22 \\
\hline \multicolumn{5}{|l|}{ Individual LSB: } \\
\hline Proximal colon & $19 \cdot 53$ & 0.35 & $15 \cdot 58^{*}$ & 0.24 \\
\hline Transverse colon & $19 \cdot 10$ & 0.50 & $15 \cdot 30^{*}$ & 0.21 \\
\hline \multicolumn{5}{|l|}{ SSB: } \\
\hline Proximal colon & $20 \cdot 05$ & $0 \cdot 30$ & $18 \cdot 86^{\mathrm{NS}}$ & 0.66 \\
\hline Transverse colon & $22 \cdot 11$ & $0 \cdot 38$ & $21 \cdot 58 \mathrm{NS}$ & 0.22 \\
\hline Frequency MSB (sequences/h) & $1 \cdot 2$ & $0 \cdot 2$ & $0.9^{\mathrm{NS}}$ & $0 \cdot 4$ \\
\hline
\end{tabular}

NS, not significant; DM, dry matter.

Mean value was significantly different from that for the basal diets: * $P<0.05$.

$\uparrow$ For details of diet, see p. 550 .

propagated aborally at a velocity of 215 (SE 31 ) $\mathrm{mm} / \mathrm{min}$ (range $4.3-51 \mathrm{~mm} / \mathrm{min}$ ). In pigs on the milk diet, they lasted only 2-3 min and the LSB not grouped into MSB were prominent (Fig. 2), so these MSB did not give a cyclical aspect to the integrated records (Fig. 4).

. The effects of diets containing IP on colonic myoelectric activity in dogs and pigs are 
Table 4. Colonic motility index (\% of maximum activity seen during feeding) in dogs and pigs 5-8 h after a meal with and without indigestible particles (IP)

(Mean values with their standard errors for nine determinations)

\begin{tabular}{|c|c|c|c|c|c|}
\hline & \multirow{2}{*}{$\begin{array}{l}\text { Period after } \\
\text { meal (h) }\end{array}$} & \multicolumn{2}{|c|}{$\begin{array}{l}\text { Diet } \uparrow \text { without } \\
\text { IP }\end{array}$} & \multicolumn{2}{|c|}{$\begin{array}{c}\text { Diet + } \\
100 \mathrm{~g} \mathrm{IP} / \mathrm{kg} \mathrm{DM}\end{array}$} \\
\hline & & Mean & SE & Mean & $\mathrm{SE}$ \\
\hline \multicolumn{6}{|l|}{ Dogs: } \\
\hline \multirow[t]{3}{*}{ Proximal colon } & $5-6$ & 95.67 & 0.85 & $61 \cdot 67^{*}$ & 0.43 \\
\hline & $6-7$ & 96.48 & 0.79 & $62 \cdot 35^{*}$ & 0.76 \\
\hline & $7-8$ & $98 \cdot 52$ & 0.81 & $58 \cdot 72^{*}$ & 0.85 \\
\hline \multirow[t]{3}{*}{ Distal colon } & $5-6$ & $75 \cdot 63$ & 0.93 & $82 \cdot 46^{*}$ & 0.69 \\
\hline & $6-7$ & $78 \cdot 41$ & 0.55 & $81 \cdot 67^{\mathrm{NS}}$ & 0.91 \\
\hline & $7-8$ & $77 \cdot 03$ & 0.75 & $83 \cdot 43^{*}$ & 1.03 \\
\hline \multicolumn{6}{|l|}{ Pigs: } \\
\hline \multirow[t]{3}{*}{ Proximal colon } & $5-6$ & $94 \cdot 53$ & 0.97 & $74 \cdot 44^{*}$ & 0.97 \\
\hline & $6-7$ & 93.96 & 0.81 & $71 \cdot 61^{*}$ & 0.89 \\
\hline & $7-8$ & $96 \cdot 23$ & 0.86 & $69 \cdot 26^{*}$ & $1 \cdot 22$ \\
\hline \multirow[t]{3}{*}{ Distal colon } & $5-6$ & $68 \cdot 88$ & 0.39 & $79 \cdot 75^{*}$ & 0.78 \\
\hline & $6-7$ & $66 \cdot 30$ & 0.45 & $75 \cdot 20^{*}$ & 0.81 \\
\hline & $7-8$ & $62 \cdot 84$ & 0.81 & $75 \cdot 62^{*}$ & 0.67 \\
\hline
\end{tabular}

NS, not significant; DM, dry matter.

Mean value was significantly different from that for the basal diet: ${ }^{*} P<0.05$.

$\uparrow$ For details of diet, see p. 550 .

summarized in Tables 2 and 3. Indigestible particles had no effect on SSB and on MSB frequency. The MSB appeared at 20-min intervals in the dog colon whatever the amount of IP. In pigs given the powdered milk diet, the colonic MSB frequency was $1 \cdot 2 / \mathrm{h}$ and although IP increased faecal excretion, MSB frequency did not significantly change. The number of individual or isolated LSB propagated orally or aborally for short distances were less frequent in the animals which had IP added to the diet. This phenomenon was more pronounced in dogs, in which the LSB activity was decreased by $58 \%$, than in pigs $(29 \%)$.

Although transit was accelerated by addition of IP to the diet, the motility index of the proximal (and transverse) colon was substantially decreased by $36 \%$ in dogs and $21 \%$ in pigs (Table 4). While the addition of IP to the diet reduced motility of the proximal colon, the motility index for the distal colon was somewhat increased in both the dog (see Fig. 3) and pig (see Fig. 4). Although these increases were only slight, about $8 \%$ in the dog and $13 \%$ in the pig, they were statistically significant $(P<0.05$, see Table 4$)$.

\section{DISCUSSION}

All values from motility studies, motility index and retention times were obtained after a $5 \mathrm{~d}$ adaptive period to each diet. During the 3-4 d following a diet change, intestinal adaptation was progressive (Fig. 1). Therefore, any determination of faecal excretion or motility index before $5 \mathrm{~d}$ after diet change would probably be in error. In fact, after refeeding the plastic pellets, there was a progressive increase in the output of faeces before settling down to a new balance. If the colonic capacity were unable to make some immediate adjustment to the change in volume of colonic contents caused by the IP, we would have expected to see a much more rapid increase in faecal volume. However, since the increase in faecal output was slowly progressive over a $3 \mathrm{~d}$ period, it appears that the colon had the 
capacity to compensate rapidly to a larger volume of contents created by the pressure of the IP. Nevertheless, the increased content of indigestible DM in the colon due to the IP treatment was paralleled by a decreased colonic motility index.

The increased LSB associated with an increase in volume of gut contents when bran was added to a milk diet (Fioramonti \& Buéno, 1980), suggesting that the distension of the colonic wall would stimulate its motility, may be the effect of an inadequate adaptation to the high-fibre diet or an effect of the by-products of colonic fermentation of the bran. The lower motility index observed with the IP treatment could not be related to a lower volume of colonic contents, since the faecal bulk was increased.

Another explanation for such discrepancies may be that the motility index takes into account LSB of different functional significance. Electromyograms of the dog and pig colon are organized into two types of spiking activity distinguished by the duration of the spike burst. SSB are independent of the other spiking activity and localized at a single electrode. They probably correspond to the high-frequency repetitive contractions recorded by strain gauges on the proximal colon of the rabbit (Ehrlein et al. 1982) and do not participate significantly in the changes of retention time (see Tables 2 and 3). The LSB observed in these experiments were similar to those earlier described for the colon of the dog and other species (Ruckebusch \& Fioramonti, 1980). The major finding was that they could show two quite distinct motility patterns. When isolated or in groups of three to five the LSB appeared to be initiated at any point of the colon and able to progress in either direction (orally or aborally) for short distances. Only when they were grouped in a large series (from eight to twelve) did they migrate along the entire colon and always in an aboral direction. This cyclically-recurring spiking activity termed MSB was identified by Burrows \& Merritt (1983) as a major pattern of canine colonic activity and involved with propulsion of large-bowel contents. The term was used to emphasize the propagation along the whole colon of LSB in conscious dogs and did not correspond to the single spike bursts which were seen propagated in vitro on the colon of the cat (Christensen et al. 1974). Our findings are consistent with the interpretation that MSB are fundamental for the propulsion of colonic contents, since only these fused sequences of LSB were propagated over successive electrodes. However, the net effect of colonic transit may depend on a certain balance between MSB and isolated LSB activity. The increase in the rate of passage of digesta with indigestible particles despite a lower motility index in the proximal colon is therefore not paradoxical, since the decreased motility index may be mainly that of isolated LSB that are propagated orally, corresponding to a braking function. This type of LSB activity may be of more importance in dogs than in pigs.

The discrepancy between our results and other work could also originate from the different sources of 'fibre'. Perhaps volatile fatty acids produced from fermentable wheat-bran particles in dogs (Banta et al. 1979) and pigs (Bardon \& Fioramonti, 1983) could stimulate increased digesta movement. Thus the patterns of LSB (isolated and fused into MSB) could be enhanced by the VFA from wheat-bran, hence an increased transit rate paralleled by an increased motility index (Banta et al. 1979).

In our study, inert polyethylene particles were used to accelerate the rate of passage of digesta. Since these particles cannot be fermented and have no water-holding capacity, they probably increased the transit of contents entirely by their mechanical properties. Basically, our results show that it is the individual LSB activity which is reduced by the diets containing IP. These isolated or individual LSB may represent the brake-like mechanism allowing maximal water absorption by the proximal colon that has been shown in the rabbit (Tucker et al. 1979). Since the IP do not retain water, this motility pattern may no longer be necessary. Like IP, $\alpha$-cellulose is indigestible and, when given to dogs, it decreases proximal colonic motility by reduction in duration of MSB, in contrast to our finding of reduced LSB 
(Burrows \& Merritt, 1983). The interaction between LSB and MSB in controlling transit rate of contents through the canine colon needs further definition.

The slight increase in distal colonic motility with IP might also affect the proximal colon transit and motility. The descending colon and rectum are a storage site for faeces, so it may be that an increased rate of emptying of the distal large intestine would reduce obstruction to flow and decrease the distension of the colonic wall, hence the hypomotility on the proximal colon. This hypothesis is not, however, satisfactory for two reasons: (1) the faecal excretion of DM increased by more than $100 \%$ when the retention time was reduced by only $30 \%$ and so the faecal bulk in the proximal colon was greater with IP added to the diet; (2) the increase of distal colonic motility was very slight, less than $15 \%$, in comparison with the great diminution $(40 \%)$ of the motility index on the other parts of the colon.

We conclude that the acceleration of transit observed with diets containing IP probably results from the inhibition of nonfused LSB activity on the proximal colon. This suggests that LSB that are not propagated for long distances can slow progression of digesta in the colon and should be measured as a characteristic different from the sequences of LSB which we term MSB.

Critical reviewing of the manuscript by Dr R. N. B. Kay of the Rowett Research Institute, Aberdeen, Scotland, is gratefully acknowledged. The authors wish to thank Mrs Gisèle Costes for skilful technical assistance.

\section{REFERENCES}

Banta, C. A., Clemens, E. T., Krinsky, M. M. \& Sheffy, B. E. (1979). Journal of Nutrition 109, $1592-1600$.

Bardon, T. \& Fioramonti, J. (1983). British Journal of Nutrition 50, 685-690.

Burrows, C. F. \& Merritt, A. M. (1983). American Journal of Physiology 245, G301-G306.

Castle, E. J. \& Castle, M. E. (1956). Journal of Agricultural Science, Cambridge 47, 196-204.

Christensen, J., Anuras, S. \& Hauser, R. L. (1974). Gastroenterology 66, 240-247.

Ehrlein, H. J., Reich, H. \& Schwinger, M. (1982). Quarterly Journal of Experimental Physiology 67, 407-417.

Fioramonti, J. \& Buéno, L. (1980). British Journal of Nutrition 43, 155-161.

Harvey, R. F., Pomare, E. W. \& Heaton, K. W. (1973). Lancet i, 1278-1280.

Hellendoorn, E. W. (1978). In Topics in Dietary Fiber Research, pp. 127-168 [G. A. Spiller, editor]. New York: Plenum Press.

Kirwan, W. O., Smith, A. N., McConnell, A. A., Mitchell, W. A. \& Eastwood, M. A. (1974). British Medical Journal 4, 187-199.

Latour, A. (1973). Annales de Recherches Vétérinaires 4, 347-353.

Latour, A. \& Ferré, J. P. (1985). Journal of Biomedical Engineering 6, (In the Press).

Ruckebusch, Y. (1970). Journal of Physiology 210, 857-882.

Ruckebusch, Y. \& Buéno, L. (1977). Gastroenterology 73, 1309-1314.

Ruckebusch, Y. \& Fioramonti, J. (1980). Zentralblatt für Veterinärmedizin A 7, 1-8.

Sarna, S. K., Condon, R. \& Cowles, V. (1984). American Journal of Physiology 246, G355-G365.

Stephen, A. M. \& Cummings, J. H. (1979). Gut 20, 722-729.

Tucker, H. J., Snape, W. J. \& Cohen, S. (1979). American Journal of Physiology 237, E383-E388. 